\title{
El momento en que se produce la interrupción civil de la prescripción (Corte Suprema)
}

\section{Comentario de Bernardo Aylwin Correa*1}

Santiago, diez de octubre de dos mil dieciocho.

\section{VISTOS:}

En autos Rol N ${ }^{\circ}$ C 9415 del Juzgado de Letras de Litueche, sobre querella de restablecimiento, caratulados "López con López", por sentencia de siete de abril de dos mil quince, se acogió la excepción de prescripción opuesta por el demandado, omitiendo pronunciamiento sobre el fondo del asunto.

Se alzó la parte demandante y la Corte de Apelaciones de Rancagua, por decisión de diecisiete de marzo de dos mil diecisiete, la confirmó. En contra de este último pronunciamiento, la demandante dedujo recurso de casación en el fondo, solicitando la invalidación del fallo y la consecuente dictación de una sentencia de reemplazo que rechace la excepción de prescripción y acoja la querella posesoria deducida.

Se ordenó traer los autos en relación.

\section{CONSIDERANDO:}

Primero: Que el recurrente denuncia la infracción del artículo 928 del Código Civil, en relación con el artículo 2514 del mismo cuerpo legal, que sostiene sobre la base de dos reproches, a saber: por un lado, critica que se haya computado el plazo de prescripción de la acción impetrada a partir de la fecha en que se verificaron los hechos de fuerza que sustentan su querella, acaecidos el 21 de mayo de 2015, en circunstancias que tales sucesos se denunciaron el día 27 de junio de ese año, pues son varios hechos de fuerza en que habría incurrido el demandado; y, por otro, censura que se haya estimado concurrente el plazo de prescripción considerando la época de notificación de la demanda, pues, conforme lo establece jurisprudencia de esta Corte, el efecto extintivo del instituto en comento es una sanción para la inactividad del acreedor que desaparece

* Licenciado en Ciencias Jurídicas y Sociales, Universidad de Chile. Abogado. Correo electrónico: baylwin@ebarros.cl 
por el solo hecho de presentar la demanda, y siendo que la notificación de la misma, no depende exclusivamente del actor o acreedor, no debe considerarse como un elemento constitutivo de la interrupción, de modo que, considerando que la demanda se interpuso en octubre de 2015, no procede acoger la excepción deducida, máxime, tratándose de una de corto tiempo. Termina señalando la forma en que las referidas infracciones habrían influido en lo dispositivo del fallo.

SEGUNDO: Que la sentencia impugnada se pronunció solamente respecto la excepción de prescripción opuesta por el querellado, y al acogerla, omitió pronunciamiento sobre el fondo del asunto. Dicha conclusión fue adoptada considerando que la querella de restablecimiento tiene un plazo especial de prescripción extintiva, consagrado por el artículo 928 del Código Civil, que es de seis meses.

En la especie, los jueces del grado, consideraron como hecho no controvertido que el querellado cerró el retazo de 126,272 metros cuadrados aproximadamente del terreno materia de autos, con fecha 21 de mayo de 2015, y que es a dicha actividad a la cual el recurrente le asigna la calidad de "despojo violento" para efectos de configurar el interdicto invocado. Por otro lado, que la querella de restablecimiento se presentó el día 22 de octubre de 2015, conforme da cuenta el timbre de cargo, siendo notificada el día 14 de diciembre de 2015.

Tercero: Que la sentencia impugnada sostuvo, al resolver la excepción de prescripción extintiva opuesta, que, a la luz del artículo 928 del Código Civil, tiene un plazo especial de seis meses, contado desde la fecha del despojo, que se reconoce que ocurrió el 21 de mayo de 2015, razón por la cual, conforme a la norma citada, la actora debió notificar válidamente su querella hasta el 21 de noviembre de ese año, pues su solo ingreso, ocurrido el 22 de octubre de 2015, no es suficiente para interrumpir civilmente la prescripción, efecto que solo se produce con la notificación legal de la demanda, momento en que se entiende trabada la Litis, que, en la especie, acaeció el 14 de diciembre de 2015, data a la cual, el plazo especial de seis meses ya había transcurrido íntegramente. Sobre la base de dicho razonamiento, acogió la excepción opuesta, y omitió pronunciamiento sobre la querella planteada, sin costa.

\section{[...]}

SExto: Que, en la segunda parte del recurso, se plantea si la prescripción extintiva que afecta a la querella de restablecimiento se interrumpe con la sola presentación de la demanda ante el tribunal dentro del plazo, o es necesario, además, su notificación dentro del mismo, señalando que existe jurisprudencia de esta Corte en la que se sostiene que la mera presentación de la demanda provoca dicho efecto, siendo su notificación solo una condición para alegarla.

SÉPTimo: Que la prescripción, en cuanto modo de extinguir las obligaciones y acciones, tiene como fundamento dogmático, según la doctrina: propender a la estabilidad de 
situaciones existentes, a fin de mantener el orden y tranquilidad sociales, erigiéndose como un obstáculo a dicha finalidad que los derechos de las partes se mantengan en la incertidumbre; afianzar definitivamente una situación de hecho que se ha manifestado pública y pacíficamente, por un largo espacio de tiempo, con el sello de la legalidad; evitar litigios acerca de hechos o situaciones que escapan a toda prueba o comprobación, pues, de lo contrario, los deudores tendrían que conservar las pruebas de la extinción de las obligaciones asumidas durante un largo tiempo, que puede tornarse indefinido; la presunción de pago o de satisfacción de la respectiva obligación que se genera a partir de la conducta asumida por el acreedor y que consiste, precisamente, en no ejercer la acción judicial respectiva ante los tribunales para obtener su satisfacción forzada; la presunción de abandono del derecho a la prestación debida de parte del acreedor; sancionar al acreedor por su negligencia en el ejercicio de los derechos consagrados en las leyes, por no iniciar a tiempo las acciones judiciales tendientes a su reconocimiento, esto es, por su inactividad prolongada y culpable. (Fueyo Laneri, Fernando, "Derecho Civil. De las obligaciones", Tomo $4^{\circ}$, Volumen II, Imprenta y Litografía Universo, Santiago, Chile, 1958, pp. 234-236, y Domínguez Benavente, Ramón, “Algunas consideraciones sobre la prescripción”. En: Revista de Derecho Universidad de Concepción 15 (59): ene.-mar. 1947, pp. 721-723).

Octavo: Que dicho instituto, de evidente naturaleza de orden público, puede verse enervado en su operatividad frente a ciertas conductas de alguna de las partes, pues, si el acreedor ejerce las acciones judiciales pertinentes o el segundo reconoce la obligación, expresa o tácitamente, el curso del término legal se interrumpe, civil o naturalmente, según sea el caso, conforme lo ordena el artículo 2518 del Código Civil. De esta manera, la interrupción civil del curso del plazo para declarar la prescripción extintiva, conforme lo señala el artículo mencionado, se produce por la demanda judicial, salvo que concurran las situaciones enumeradas en el artículo 2503 del mismo cuerpo legal, que son los siguientes: $1^{\circ}$ si la notificación de la demanda no ha sido hecha en forma legal; $2^{\circ}$ si el recurrente desistió expresamente de la demanda o se declaró abandonada la instancia; y $3^{\circ}$ si el demandado obtuvo sentencia de absolución.

Ahora bien, a juicio de esta Corte, la interpretación correcta de dichas normas es aquella que entiende que la interrupción civil del plazo de prescripción extintiva, se produce con la notificación judicial de la demanda, efectuada en forma legal, actuación que impide que se complete el plazo de que se trata; pues pretender que para ello basta la sola presentación del libelo, aunque supeditada a su notificación judicial posterior, significaría, en primer lugar, que quedaría al arbitrio del demandante la determinación de la época en que la interrupción se consolidaría, lo que ocurriría solo cuando decida que se lleve a cabo la notificación, efectuando el encargo al ministro de fe competente; en segundo lugar, no se entendería la excepción del número 1 del artículo 2503 ya que si no se produce la interrupción en el caso de notificación ilegal de la demanda, menos se entenderá que la interrumpe si no ha sido notificada de modo alguno; y, en tercer lugar, porque con dicha postura se estaría dotando a la dicha actuación judicial de un efecto retroactivo que la legislación nacional no le otorga ni reconoce, pues, en definitiva, 
habría que entender que si una demanda, v. gr., se presentó con la data de la presente sentencia y se notifica en diez años más, la interrupción civil se produjo en la primera fecha, esto es, una década antes.

Tal situación sería plenamente factible, desde que nuestra legislación no contempla, como en el derecho comparado, una norma que de modo expreso establezca una regla de interrupción civil provocada con la presentación de la demanda, pero sujeta a un plazo expreso para efectos de concretar su notificación.

Así sucede, por ejemplo, en el sistema colombiano, donde el artículo 94 inciso primero del Código General del Proceso, señala que: "La presentación de la demanda interrumpe el término para la prescripción e impide que se produzca la caducidad siempre que el auto admisorio de aquella o el mandamiento ejecutivo se notifique al demandado dentro del término de un (1) año contado a partir del día siguiente a la notificación de tales providencias al demandante. Pasado este término, los mencionados efectos solo se producirán con la notificación al demandado". Una norma similar contempla el artículo 2892 del Code Civil du Québec, que establece que el plazo para notificar una demanda presentada antes de expirar el plazo de prescripción, es de sesenta días contados desde el vencimiento de dicho término legal. En el mismo sentido, el Novo Código de Processo Civil de Brasil, contempla en su artículo 240, acápite primero, la regla de que la interrupción de la prescripción, operada por el despacho que ordena la citación, se retrotraerá a la fecha de presentación de la acción. En el apartado segundo, señala que le incumbe al actor adoptar, dentro del plazo de 10 días, las providencias necesarias para viabilizar la citación, bajo pena de no aplicarse lo dispuesto en el primer parágrafo citado.

Noveno: Que, a mayor abundamiento, se debe precisar que la falta de notificación de la demanda constituye un obstáculo insoslayable para que se inicie el juicio, que no puede imputarse sino a la indolencia del demandante, desde que nuestro ordenamiento contempla herramientas procesales suficientes como para no admitir la excusa de la imposibilidad de practicar la notificación, por ejemplo, por ser inubicable el demandado, una muestra de ello lo constituye la posibilidad de notificación conforme el artículo 54 del Código de Procedimiento Civil y la eventual designación de un defensor de ausentes. De este modo, se hace palmario que es la pasividad o desidia del acreedor el fundamento de una de las situaciones a que alude el número 2 del artículo 2503 del Código Civil, a saber, el abandono del procedimiento, la que, a diferencia de la prescripción, sanciona la negligencia del demandante por no realizar las gestiones útiles para hacer avanzar el procedimiento hasta su conclusión normal. Tratándose de las demás situaciones que señala dicha norma legal es decir, el desistimiento de la demanda y la dictación de una sentencia absolutoria, que presentándose del mismo modo obstan a que opere la interrupción civil, implican, necesariamente, que al demandado se le dio noticia de la interposición de una demanda en su contra para obtener que cumpla su obligación y, obviamente, no puede provocar el efecto a que se hace referencia por la actitud voluntaria asumida por el actor, ya que el desistimiento genera, conforme lo establece el artículo 150 del Código de Procedimiento Civil, la 
extinción de las acciones a que él se refiere, con relación a las partes litigantes y a todas las personas a quienes habría afectado la sentencia del juicio a que se pone fin. En lo que concierne al segundo caso, porque el actor no logró acreditar los presupuestos de su pretensión.

Décimo: Que, entenderlo de la manera que el recurrente pretende, significaría que serían letra muerta las disposiciones que consagran la interrupción natural de la prescripción y las obligaciones naturales, como también la que autoriza al deudor a renunciar al derecho a alegar la prescripción extintiva, pues no obstante tener pleno conocimiento de la oportunidad en que empezó a correr el término legal necesario para que opere la prescripción como medio de extinguir las acciones y derechos ajenos, que no es sino a contar de la época en que la obligación se hizo exigible, desconocería la oportunidad en que el plazo se interrumpió civilmente, al entenderse que ello ocurre con la mera presentación de la demanda, por lo tanto, nunca podría interrumpirlo naturalmente, ni tener la certeza si está solucionando una obligación natural, menos renunciar al derecho a alegar en juicio el medio de extinguir a que se hace referencia. Tampoco deducir una demanda en juicio ordinario solicitando que se declare la prescripción extintiva, por haber transcurrido el término legal. Lo anterior conduce a una situación paradójica, esto es, la instauración de instituciones que, en definitiva, es muy difícil o imposible que se configuren; sin perjuicio de que podría llegarse a una situación extrema, que nunca transcurra el plazo de que se trata si llegada la época de vencimiento de la obligación o el hecho que la genera, el acreedor deduce de inmediato la respectiva demanda, sin notificarla. Y lo más grave, es que no aplicarían solamente para aquellos insolventes cuyas deudas no constan en letras de cambio y pagarés, porque figurando en dichos instrumentos, aplica lo que dispone el artículo 100 de la Ley $\mathrm{N}^{\circ}$ 18.092, con ello, toda las instituciones relacionadas con el modo de extinguir a que se hace referencia; contexto que autoriza colegir que el estado de incertidumbre que la prescripción extintiva pretende derrotar afectaría únicamente a los primeros y a quienes consintieron responder por aquéllos constituyendo una garantía real o personal, pues el artículo 2516 del Código Civil señala que "La acción hipotecaria, y las demás que proceden de una obligación accesoria, prescriben junto con la obligación a que acceden”.

Undécimo: Que, por lo demás, este ha sido el criterio asumido por esta Corte, al comprender de manera estable que la correcta comprensión del artículo 2503 del Código Civil, lleva a considerar que la sola presentación de la demanda "no es suficiente para entender efectivamente interrumpida la prescripción, puesto que la demanda debe notificarse al deudor y esa notificación ha de cumplir los requisitos establecidos en la ley. Por ello, si posteriormente se anula la notificación efectuada, el resultado es que la prescripción no se habrá interrumpido. Lo mismo ocurrirá en caso que el pleito en el cual se haya producido el fenómeno interruptor en mención termine en la absolución del demandado, hipótesis en la que, aunque detenido el curso de la prescripción por la notificación válida de la demanda, este efecto se pierde ante ese fallo que aprovecha al 
sujeto pasivo del proceso" (Ingreso Corte Suprema No 93.002 16, sentencia de 14 de septiembre de 2017), asumiéndose, de este modo, el criterio adoptado por la disidencia plasmada en los antecedentes de esta Corte $\mathrm{N}^{\circ} 7.407$ 16, en fallo dictado el 7 de junio de 2017.

Duodécimo: Que, de este modo, se concluye de manera incontestable que a la sola presentación del interdicto posesorio de que se trata, no se le puede asignar la potestad ni virtud de interrumpir el breve y especial término de prescripción que corría en contra del recurrente para deducir la querella de restablecimiento, puesto que dicho efecto solo se podía concretar con la notificación válida de dicha actuación, de manera que el fallo impugnado no incurrió en error de derecho al fallar como lo hizo, por lo que, descartándose las infracciones de ley acusadas, el recurso en estudio debe ser desestimado.

Por estas consideraciones y visto, además, lo dispuesto en los artículos 765 y 767 del Código de Procedimiento Civil, se rechaza el recurso de casación en el fondo interpuesto en contra de la sentencia de diecisiete de marzo dos mil diecisiete, que se lee a fojas 94, dictada por la Corte de Apelaciones de Rancagua.

Regístrese y devuélvase.

$\mathrm{N}^{\circ} 12.238-17$.

Pronunciado por la Cuarta Sala de la Corte Suprema integrada por la Ministra señora Gloria Ana Chevesich R., Ministros Suplentes señores Julio Miranda L., Juan Muñoz P. y los abogados integrantes señora Leonor Etcheberry C., y señor Iñigo De la Maza G. No firma el Ministro señor Miranda, no obstante haber concurrido a la vista y al acuerdo de la causa, por haber terminado su período de suplencia. Santiago, diez de octubre de dos mil dieciocho.

\section{Comentario}

La sentencia transcrita, relativa al momento en que se produce la interrupción civil de la prescripción, es destacable en varios aspectos. En primer lugar, pretende poner término a una inquietante disputa jurisprudencial sostenida en los últimos años. Luego, aporta luces respecto de la perspectiva con la que se debe abordar el asunto sometido a su decisión. Finalmente, su razonamiento da espacio para avanzar en una adecuada solución de la cuestión.

1. Con base en los artículos 2503 y 2518 del Código Civil se ha discutido si la prescripción se interrumpe al momento de la presentación de la demanda judicial ("Tesis de la Acción”) o al de su notificación hecha en forma legal (“Tesis de la Notificación”). La cuestión adquiere relevancia en aquellos casos en que el plazo de prescripción se cumple entre la presentación de la acción y su notificación. 
Tradicionalmente, la doctrina y jurisprudencia concluían que el efecto interruptor se producía con la notificación de la demanda. Por el contrario, un sector minoritario postulaba que la interrupción tenía lugar al momento de presentarse la acción, sujeta, por cierto, a que ella se notificara ${ }^{1}$. En todo caso, la cuestión no despertaba gran interés, pues la jurisprudencia sistemáticamente se inclinó por la primera tesis.

Sin embargo, el 31 de mayo de 2016 la cuarta sala de la Corte Suprema señaló que "es tiempo de variar el criterio mayoritario", inclinándose por adoptar la Tesis de la Acción (rol N 6.900-15). Para sustentar su posición la Corte abogó por distinguir los efectos civiles y procesales de la notificación. Así, mientras en el ámbito adjetivo la notificación adquiere relevancia al configurar el inicio de la relación procesal, sustantivamente no correspondería atribuirle el efecto interruptor a este acto. Agregó que esta solución sería coherente con el fundamento de la prescripción, que consistiría en sancionar la negligencia del titular del derecho. Finalmente, la Corte señaló que esta solución ha encontrado acogida en derecho comparado.

Esta sentencia hizo revivir la antigua controversia en torno al momento en que se produce la interrupción civil de la prescripción. Doctrinariamente, se generó un intenso e interesante debate entre quienes apoyan y critican la solución adoptada por la senten$\mathrm{cia}^{2}$. Jurisprudencialmente, se produjo una inquietante disputa al interior de la Corte Suprema. En concreto, mientras la primera, segunda y tercera sala mantuvieron su apoyo a la Tesis de la Notificación, la cuarta sala defendió el cambio de criterio, argumentando en favor de la Tesis de la Acción ${ }^{3}$. Esta circunstancia resultaba particularmente preocupante, pues introducía un importante elemento de incertidumbre en la aplicación de una institución que, como veremos, está orientada a otorgar certeza jurídica.

Sin embargo, mediante el fallo analizado, la cuarta sala modificó su posición de los últimos años y volvió a abrazar la Tesis de la Notificación. Al efecto, la Corte Suprema inicia su razonamiento exponiendo los fundamentos de la prescripción y la forma en

${ }^{1}$ Por la Tesis de la Notificación, Meza Barros, Ramón, De la interrupción de la prescripción extintiva civil, Santiago, Universidad de Chile, Facultad de Ciencias Jurídicas y Sociales, 1936, pp. 42 ss. En la jurisprudencia, Corte Suprema, 9 de abril de 2001, RDJ, T. XCVIII, sec. 1ª , p. 71. Por la Tesis de la Acción, Domínguez Águila, Ramón, La prescripción extintiva, doctrina y jurisprudencia, Santiago, Ed. Jurídica de Chile, 2004, p. 263. En la jurisprudencia, Corte de Apelaciones de Valparaíso, 29 de octubre de 1963, RDJ, T. LX, sec. $2^{\text {a }}$, p. 130. Con todo, debe advertirse que existen leyes especiales que escapan de la regulación del Código Civil (por ejemplo, artículos 100 de la Ley No 18.092 (1982) y 54 de la Ley N 15.231 (1978)).

${ }^{2}$ En favor de la sentencia: Domínguez ÁGuila, Ramón, "Sobre la interrupción civil de la prescripción extintiva. Basta la sola interposición de la demanda", en Revista de derecho Universidad de Concepción, N ${ }^{\circ} 239$, Concepción, 2016, p. 245; PiZArro, Carlos, "La interrupción civil de la prescripción por la mera presentación de la demanda”, en Estudios de Derecho Civil, T, XII, Santiago, 2017, p. 161. En contra: PinocheT, Ruperto, "La notificación de la demanda debe efectuarse dentro del plazo de prescripción para interrumpir civilmente la prescripción", en Estudios de Derecho Civil, T, XII, Santiago, 2017, p. 173; AlCalde, Jaime, "Sobre la eficacia procesal de la demanda que interrumpe la prescripción extintiva, en Estudios de Derecho Civil, T. XII, Santiago, 2017, p. 189.

3 Por la Tesis de la Notificación: Corte Suprema, 4 de julio de 2018, rol No 38.135-17 (1 ${ }^{\text {a }}$ sala), Corte Suprema, 3 de abril de 2017, rol No 18.306-16 (2 $2^{\mathrm{a}}$ sala), Corte Suprema, 21 de marzo de 2018, rol

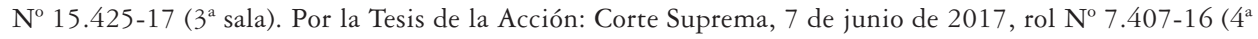
sala) y Corte Suprema, 25 de julio de 2018 , rol No $43.450-17$ ( $4^{\mathrm{a}}$ sala). 
que opera la interrupción, para luego detenerse en el desarrollo de los argumentos que justifican su decisión. Así, se refiere al texto expreso del artículo $2503 \mathrm{~N}^{\circ} 1$ del Código Civil y a los múltiples problemas que supondría adoptar la Tesis de la Acción. Fundamentalmente, la Corte advierte que dotar de un efecto retroactivo a la notificación implicaría que el titular del derecho podría interrumpir indefinidamente la prescripción sin que el demandado tenga siquiera conocimiento de ello. Agrega que, a diferencia de otras legislaciones, nuestro ordenamiento no contiene normas que permitan evitar estas maniobras.

2. La cuestión sometida al conocimiento de la Corte no es de fácil solución. Adoptar la Tesis de la Notificación supone que en ciertos casos el titular del derecho se verá impedido de interrumpir la prescripción por circunstancias ajenas a su control (maniobras elusivas del demandado, por ejemplo). Favorecer la Tesis de la Acción, por otro lado, implica asumir que el demandante puede interrumpir la prescripción sin tener interés alguno en reclamar efectivamente el derecho y, lo que resulta más problemático, sin que el demandado tenga conocimiento de la interrupción.

En ausencia de una norma que resuelva inequívocamente la cuestión, nuestros tribunales suelen optar por soluciones que estiman coherentes con los fines de la prescripción. Así, en la medida que consideran que esta institución tiene por objeto otorgar certeza jurídica, concluyen que su interrupción requiere de un acto recepticio que se materializaría con la notificación. En contraposición, concebida como una sanción a la negligencia del titular del derecho, sostienen que corresponde distinguir entre el efecto procesal y civil de la notificación, de modo que, en el aspecto sustantivo, la interrupción no se vería afectada por la falta de conocimiento del demandado, pues lo realmente relevante sería la intención de reclamar el derecho.

En este escenario, la cuarta sala de la Corte Suprema identifica adecuadamente el quid del asunto y, tomando un giro respecto de lo sostenido en los últimos años, le otorga preeminencia al denominado fundamento objetivo de la prescripción, concluyendo que el conocimiento del demandado debe ser un elemento constitutivo de la interrupción (considerandos séptimo y décimo). El razonamiento en torno a los fines de la prescripción parece acertado, pues, en la medida que el ordenamiento jurídico valora las apariencias y expectativas creadas y supone que el paso del tiempo dificulta las opciones de defensa, existen buenas razones para considerar que el fin último de la prescripción está orientado a proteger intereses generales, promoviendo que el transcurso del tiempo estabilice relaciones jurídicas inciertas. Así, la prescripción no constituye un fin en sí mismo, sino un medio para otorgar certeza jurídica ${ }^{4}$. Desde luego, la negligencia del titular del derecho ayuda a justificar los efectos desfavorables de la prescripción, pero no constituye el único motivo, ni, por cierto, su razón de ser.

${ }^{4}$ Díez-PiCazo, Luis, Fundamentos del Derecho Civil Patrimonial, T. III, Navarra, Editorial Aranzadi, 2008, pp. 787 ss.; y Zimmermann, Reinhard, Comparative Foundations of a European Law of Set-Off and Prescription, Cambridge University Press, Cambridge, 2002, pp. 66 ss. 
3. Igualmente, la determinación del momento en que se produce la interrupción de la prescripción no se agota con este análisis. Si bien determinar los fines de la institución otorga luces para definir el momento interruptor, esta sola consideración no es suficiente para adoptar la Tesis de la Notificación, como parece haberlo entendido tradicionalmente la jurisprudencia.

Aunque es cierto que los fines de la prescripción hacen aconsejable que su interrupción constituya un acto concreto y conocido, no por ello debiese descartarse a todo evento la Tesis de la Acción. La presentación de la demanda constituye un acto preciso y público que, en la generalidad de los casos, es puesta en conocimiento del demandado tan pronto resulta posible. Así, no obsta a los fines de la prescripción que el efecto interruptor se produzca con la presentación de la acción, que será prontamente notificada. Los críticos de esta tesis rebaten que ella permite al demandante interrumpir indefinidamente la prescripción sin tener un interés real en reclamar su derecho, como en los casos en que el actor no notifica la demanda. Al respecto, explican que el artículo $2503 \mathrm{~N}^{\circ} 2$ no puede evitar esta circunstancia, pues el abandono del procedimiento solo puede declararse una vez notificada la demanda.

Sin embargo, no parece razonable adoptar una solución general con el único propósito de evitar situaciones marginales, máxime si consideramos que la técnica legislativa procesal tiende a evitar estas conductas del actor ${ }^{5}$. En cualquier caso, debe advertirse que el ordenamiento jurídico contempla mecanismos que permiten solucionar estas circunstancias. Así, en la medida que el tribunal concluya que la demora o ausencia de notificación no resultó justificable, puede privar de efecto interruptor a la demanda, concluyendo que, en la especie, el titular del derecho incurrió en una conducta dolosa, contraria a la buena fe o abusiva de derecho que, por tanto, satisface el supuesto de hecho previsto en el artículo $2503 \mathrm{~N}^{\circ} 1$ del Código Civil ${ }^{6}$. En este sentido, en Alemania se ha resuelto que la suspensión de la prescripción por demanda judicial se produce al momento de la interposición de la acción, bajo la carga de que el demandante sea diligente en promover la notificación en un plazo prudente. Del mismo modo, los tribunales ingleses favorecen la Tesis de la Acción sujeta a ciertos criterios de razonabilidad ${ }^{7}$.

Este razonamiento puede ser replicado por nuestros tribunales. Un examen de la jurisprudencia permite concluir que la Tesis de la Notificación se ha aplicado indistintamente en aquellos casos en que media un largo y desproporcionado plazo

${ }^{5}$ Los nuevos procedimientos contemplan que la primera notificación se efectúe por un funcionario del tribunal, dispensando al actor de esa carga (por ejemplo, artículos 23 de la Ley Nº 19.968 (2004) y 436 del Código del Trabajo). Por otro lado, el proyecto de Código Procesal Civil prevé la figura de la caducidad del procedimiento en el caso que el demandante no provea antecedentes necesarios para efectuar la primera notificación (artículo 114 del boletín 8197-07).

${ }^{6}$ Corral Talciani, Hernán, Interrupción Civil de la Prescripción; ¿ giro jurisprudencial? Disponible en https://corraltalciani.wordpress.com/2016/06/26/interrupcion-civil-de-la-prescripcion-giro-jurisprudencial/. [Fecha de consulta: 30.04.2019]

${ }^{7}$ Alemania: BGH, 12 .07.2006 - IV ZR 23/05. En el mismo sentido 23 U 261/13 Frankfurt. Inglaterra: Rinikerv University College London [1999] EWCA Civ 1156. 
entre la interposición de la acción y su notificación y aquellos en que la demanda fue notificada en un plazo prudente ${ }^{8}$. Desde luego, no parece razonable privar de efecto interruptor a la acción que fue ejercida dentro del plazo de prescripción y notificada prontamente, pues no supone riesgo alguno a los fines de la prescripción y, en todo caso, no constituye un caso de interrupción indefinida. Esta situación se ve agravada, además, en el caso de acciones que cuentan con un plazo corto de prescripción, como el de la sentencia analizada.

La solución propuesta es consistente con el texto de la ley, que no exige la notificación de la demanda dentro del plazo de prescripción. Objetivamente, las excepciones previstas en el artículo 2503 del Código Civil obedecen a la concepción de que el efecto interruptor se produce con la sentencia judicial, de suerte que, previo a ella, la prescripción se interrumpe solo provisoriamente ${ }^{9}$. Así, la exigencia de notificación hecha en forma legal atiende a que la acción tenga la aptitud de provocar una sentencia que reconozca el derecho reclamado, lo que no obsta a que el efecto interruptor provisorio se produzca con la interposición de la demanda. La noción de que el efecto interruptor se produce con la notificación de la demanda parece originarse en el antiguo artículo 2244 del Código Civil francés que otorga dicho efecto a la citation en justice, que algunos autores identificaron equivalente al emplazamiento. Asimismo, tanto la doctrina como la jurisprudencia de ese país comprendieron que la norma alude a la acción, lo que fue expresamente recogido en la reforma a la prescripción civil del 2008 (actual artículo 2241). Otras legislaciones influenciadas por el Code han arribado a conclusiones similares ${ }^{10}$.

Una vía alternativa, como lo indica la sentencia transcrita, consiste en adoptar la solución prevista en algunas legislaciones que expresamente dotan de efecto interruptor a la acción, bajo la condición de que se efectúe la notificación en un plazo determinado (Colombia, Quebec y Brasil, por ejemplo). En cualquier caso, debe advertirse que estas reglas no son más que la concreción legal del principio de que la interrupción civil se produce al momento de interposición de la acción, siempre que el titular del derecho tenga un interés real en proseguir con el juicio y lo demuestre mediante actos concretos que tiendan a la notificación de la demanda. Así, la ausencia de una norma que prevea esta situación no impide que nuestros tribunales adopten soluciones en este sentido.

${ }^{8}$ Por los primeros, Corte Suprema, 20 de febrero de 2017, rol No 41.190-16; Corte Suprema, 20 de marzo de 2017, rol No 62.200-16, entre otros. Por los segundos, Corte Suprema, 4 de julio de 2018, rol $\mathrm{N}^{\circ} 38135-17$, entre otros.

9 Díez-Picazo, La Prescripción Extintiva, Navarra, Editorial Aranzadi, 2007, p. 159; Corte Suprema, 14 de septiembre de 2017, rol N 93002-16. Incluso, en legislaciones modernas como Alemania y los Principios de Derecho Europeo de Contratos la acción del titular del derecho suspende la prescripción hasta la dictación de la sentencia (Zimmermann, Reinhard, The New German Law of Prescription and Chapter 14 of the Principles of European Contract Law, en The New German Law of Obligations, Chapter 5. Oxford University Press, 2005, pp. 13 s).

${ }^{10}$ En Francia: Ripert, Georges, Tratado de Derecho Civil, según el tratado de Planiol, Volumen 5, Buenos Aires, La Ley 1963-1965 pp. 620 ss.; Domínguez Águila, op. cit., p. 262 y la jurisprudencia allí citada. En España, Díez-Picazo, La Prescripción Extintiva, Navarra, Editorial Aranzadi, 2007, pp. 160 ss. 
En definitiva, la sentencia analizada es destacable, pues pretende poner fin a la delicada situación de incertidumbre al interior de la Corte Suprema. En cualquier caso, parece aconsejable avanzar en una solución jurisprudencial o legislativa que, en armonía con los fines de la prescripción, permita ponderar adecuadamente el interés social de certeza jurídica con el interés del titular del derecho que pretende ejercerlo diligentemente. 
